\title{
Effectiveness of Yoga Therapy on Low Back Pain among Women
}

\section{Shivaji KK* \\ Professor of Pravara Institute of Medical Sciences, College of Nursing, India}

*Corresponding author: Kalpana Kale Shivaji, College of Nursing , PIMS (DU) A/p -

Loni, Maharashtra, India, Email: kalpana_kale70@yahoo.in

\section{Research Article \\ Volume 3 Issue 1}

Received Date: January 04, 2019

Published Date: April 26, 2019

DOI: $10.23880 /$ phoa- 16000135

\section{Abstract}

A quasi experimental study with one group pretest, posttest without control group approach was undertaken at the Musale vasti and Vitthalnagar in Loni village. The data was collected from 30 women who were having low back pain , selected through purposive sampling technique to assess the effectiveness of yoga therapy on Low back pain. Findings revealed that highest 74\% women were in age group between 36-40 years. Maximum $67 \%$ women have height between $150-160 \mathrm{~cm} .50 \%$ of women had weight of $60 \mathrm{~kg}$ and above. Most of the $60 \%$ women had $19-25$ that is average BMI .maximum $60 \%$ of them had secondary level education. Most $74 \%$ of them were housewives. Most of them had moderate level of work and were using transport facility as Bus and two wheeler. It was found that the post test mean score of pain $(0.9 \pm 0.84)$ which is $(90 \%)$ was significantly lower than the pretest mean score and showed effectiveness of $40 \%$. It was found that the posttest mean score of disability $(12.3 \pm 2.17)$ which is $(13.2 \%)$ was significantly lower than the patient mean score and shows effectiveness of $11.4 \%$. It was evident from these findings that the yoga therapy had significant effect in minimizing the pain ( $\mathrm{t}-3.98$, at $\mathrm{p}<0.001$ ). There was significant association between pain, marital status, transport facility, associated illness and other remedial measures; and disability with weight, transport facility and other remedial measures.

Keywords: Effectiveness; Yoga therapy; Low Back Pain; Women

\section{Introduction}

Back pain is pain felt in the back that usually originates from the muscle, nerves, bone, joint or other structure in the joint. Low back pain is of the most common pain disorders today, it is chronic condition characterized by a persistent dull or sharp pain per the lower back [1].

Kimberly B (2002) reported that back pain has become a leading epidemic of which more than $80 \%$ of adults will experience sometime during their lifetime.
Singh KG \& Rupali S [2] reported that in India occurrence of low back is also alarming nearly $60 \%$ of the people in India have significant back pain at some time or other in times. The highest rate of back pain occurs among the 45 to 65 years age group. The incidence of low back pain is greater among women [3]. Study shows that Yoga is holistic practice that is prescribed as alternative or complementary rehabilitation for back pain. There are very few studies related yoga therapy and its effect on back pain are conducted in Indian scenario, thus a study carried out on assess the effectiveness of yoga therapy on back pain [4]. 


\section{Objectives}

1. To assess the level of low back pain among the women before implementing Yoga therapy.

2. To assess the level of disability among the women before implementing yoga therapy.

3 . To determine the effectiveness of yoga therapy on low back pain among the women with low back pain.

4. To determine the effectiveness of yoga therapy on disability among the women with low back pain

5. To find out association of the level of Low back pain with their selected demographic variables, after yoga therapy.

\section{Hypotheses}

H01- There is no significant difference in the level of low back pain between pre-test and post test period.
H02 - There is no significance difference in the level of disability between pre and post test period.

H03-There is no significant association between level of Low back pain and their selected demographic variables.

H04-there is no significant association between the level of disability and their selected demographic variables.

\section{Conceptual Framework}

Modified Theoretical Framework Based on Nola J Pender's Health promotion model was used for present study (Figure 1).

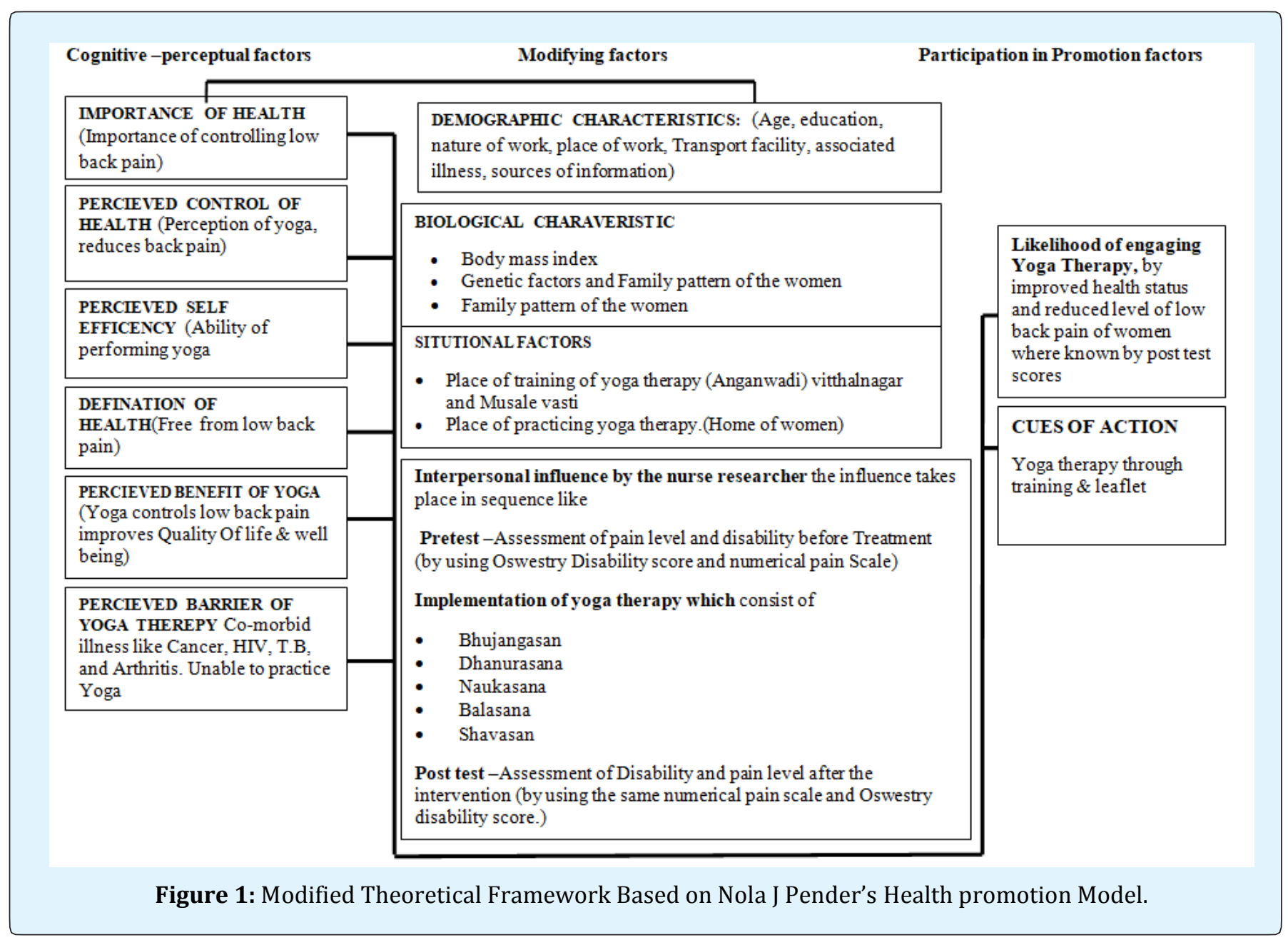

Shivaji KK. Effectiveness of Yoga Therapy on Low Back Pain Among Women. Public H Open Acc 2019, 3(1): 000135. 


\section{Methodology}

\section{Research Design}

Quasi experimental study design; pretest\&posttest without control group approach [5].

\section{Sample and Sampling Technique}

Women who are having low back pain between 30-50 years of age group who were present during the period of data collection were the sample for this study and Non Probability purposive sampling technique were used to select the 30 samples.

\section{Setting}

The present study was conducted invitthalnagar \& musalevasti at Loni, Ahmednagar (Maharashtra).

\section{Tools}

Well prepared and expert validated structured Questionnaire (socio demographic data: 14 items and 10 item of The Oswestry Low Back pain Disability questionnaires and Numerical Pain scale which consist of 0 to 10 points scale) was in the interview schedule to collect the data [6].

\section{Ethical consideration}

Prior to collection of data written permission was obtained from the sarpanch of Loni B.K. village. Informed consent was taken from all the samples prior to investigation.

\section{Data collection procedure}

Data collection was done in three stages, which is pretest, implementation of intervention (yoga therapy) and posttest. First day of study pretest was conducted to assess the disability and pain level then instructions and demonstration of yoga therapy on Bhujangasana,
Naukasan, Dhanurasana, Balasana, shavasana, followed the samples during their practice and after 30 days posttest was carried out. The collected data was organized and analyzed according to the objectives of study by using descriptive and inferential statistics.

\section{Significant Findings of Study}

Findings related to demographic data: Findings revealed that highest $74 \%$ women were in age group between $30-40$ years, $67 \%$ of women had height of 150 $160 \mathrm{~cm}, 50 \%$ had more than $60 \mathrm{~kg}$ and above, $60 \%$ women had average BMI , 70\% of them had school education, $74 \%$ were housewives, $73 \%$ of women had income of $>5000$ Rs., $70 \%$ had moderate work and transport facility used was two wheeler and Bus(47\%\&40\%respectively), only $17 \%$ had orthopedic illness and $74 \%$ had received information through mass medias [7].

Assessment of level of low back pain and disability among the women: Highest percentage $(67 \%)$ of the women had severe pain whereas $(33 \%)$ of them had moderate level of pain .Scores on disability shows maximum $(83 \%)$ of women had moderate level of disability and $17 \%$ of them had minimum disability.

\section{Effectiveness of yoga therapy on low back pain and disability \\ - N - 30}

Findings levels during pretest the mean score was $(4.9$ \pm 0.8 ) which is $49 \%$ (moderate pain) however posttest the score was $(0.9 \pm 0.84)$ which is $9 \%$ of the total score, which indicates women had mild pain in posttest and had $40 \%$ effectiveness of yoga therapy [8]. In relation to the disability during pretest mean score was $(12.3 \pm 2.17)$ which is $24.6 \%$ whereas in posttest it was $13.2 \%$ which shows the effectiveness of yoga therapy on reducing the level of disability. There was significant difference was found on pain $(t-3.98)$ and disability $(t-5.38)$ in pretest and posttest at $p>0.05$ level (Table 1 ).

\begin{tabular}{|c|c|c|c|c|c|c|c|c|}
\hline \multirow{2}{*}{ Sr No } & \multirow{2}{*}{ Area } & \multicolumn{3}{|c|}{ Pre test } & \multicolumn{3}{c|}{ Post test } & \multirow{2}{*}{ Difference in mean \% } \\
\cline { 3 - 8 } & & Mean & SD & Mean \% & Mean & SD & Mean \% & \\
\hline 1 & pain & 4.9 & 0.8 & 49 & 0.9 & 0.84 & 9 & 40 \\
\hline 2 & Disability & 12.3 & 2.17 & 24.6 & 6.6 & 1.44 & 13.2 & 11.4 \\
\hline
\end{tabular}

Table 1: Finding the levels using Pre-test and post-test.

\section{Discussion}

Women with low back pain are a growing problem in all over the world. the incidence of low back pain is greater among women. Peter A $(2005)[7,9]$ reported that back pain is the most frequent cause of activity limitation in people aged younger than 45 years. Approximately $90 \%$ of all people experience low back pain at same time and $50 \%$ of working adult have back pain. Lifetime recurrence rate of as high as $85 \%$ have been documented [10]. 
In our study findings shows that women had moderate level of pain and the disability. These findings are supported by (Wong TS.et al., 2010), conducted a study on prevalence of low back pain and disability among women, which revealed that the prevalence of low back pain was $72 \%$ with moderate level and required leave or absence from the work $[11,12]$.

However after the implementation of Yoga therapy the women had significant reduction in the level of pain and disability [13]. Similar findings were observed by Leslie G, Jeremy $\mathrm{K}$, and Laurie $\mathrm{V}$ that the women with chronic low back pain had statistical significance $(P>0.05)$ in reducing the severity of pain after the intervention (Yoga programme) [14].

\section{Conclusion}

Study findings revealed that the yoga therapy was found to be more effective on women with low back pain and disability. There was significant association found between the level of pain and the variables like marital status, transport facility and associated illness, where the level of disability had significant association with weight and transport facility. Hence the Yoga therapy is enhances the quality of life and reduces the level of back pain and disability.

\section{References}

1. Enrich G (2003) Bulletin of the world health organization, pp: 671-76.

2. Sharma SC, Sing R, Sharma AK, Mittal R (2003) Incidence of low back pain in work age adults in rural north India. Indian journal medical sciences 57(4): 45-47.

3. Koley S, Singh G, Rupali S (2008) severity of disability in elder patient with low back pain in Amritsar, Punjab. The journal Anthropologist 10(4): 265-258.
4. Kwon MA, Shim WS, Kim MH, Gwak MS, Hahm TS, et al. (2006) A correlation between low back pain and associated factors. The journal Korean medical sciences 21(6): 1086-1091.

5. Marth M (2007) yoga for back pain.

6. Wong TS, Teo N (2004) prevalence and risk factors associated with low back pain. The journal of physiotherapy 25(2): 53-58.

7. Peter $A(2018)$ The incidence of back pain.

8. Sharma SC, Singh R, Sharma AK, Mittal R (2003) Incidence of low back pain in workage adults in rural north India. Indian journal medical sciences 57(4): 145-147.

9. Patwardhan S (2010) low back pain Aurvedic management.

10. Cecilia E, Tilu H (2008) Health problem of women. The Journal of America.

11. Wong TS, Teo N, Kywn MO (2007) prevalence and risk factors associated with low Back pain among health care providers in a district hospital. The journal of physiotherapy 4(2): 23-28.

12. Elders LA, Burdorf A (2004) The prevalence and incidence of low back pain in scaffolds during 3 years follow up. Spine 29(6): E101-106.

13. Williams KA, Petronis J, Smith D, Goodrich D, Wu J, et al. (2005) effect of Iyengar Yoga therapy on chronic low back pain. The journal of pain 20(3): 107-117.

14. Leslie G, Jeremy K, Laurie V (2000) randomized, controlled, double-blinded study set out to determine the efficacy of a hath yoga program, the international journal of Alternative medicine 22(3): 530-537. 